\title{
Immediate Glucose-Lowering Effect After the First Administration of Dulaglutide: A Retrospective, Single-Center, Observational Study
}

\author{
Sakiko Terui · Ryoichi Akamatsu - Masanori Arai · Ryota Inoue • \\ Tomoko Okuyama · Mayu Kyohara · Jinghe Li · Takahiro Tsuno • \\ Daisuke Miyashita $\cdot$ Yu Togashi $\cdot$ Yasuo Terauchi $\cdot$ Jun Shirakawa
}

Received: June 29, 2021 / Accepted: August 25, 2021 / Published online: September 17, 2021

(C) The Author(s) 2021

\begin{abstract}
Introduction: Dulaglutide is a long-acting glucagon-like peptide 1 receptor agonist that is administered once weekly for the treatment of type 2 diabetes. However, the immediate glucose-lowering effect of dulaglutide after the first administration and the factors affecting the efficacy of the drug remain unclear.

Methods: This study was a retrospective and observational study of 80 subjects with type 2 diabetes conducted in a hospitalized setting. The changes $(\Delta)$ in the blood glucose (BG) levels at six time points (6-point BG levels) from the baseline (day - 1) to the day after the first administration of $0.75 \mathrm{mg}$ of dulaglutide (day 1 ) were evaluated. The associations of the $\Delta 6$ point BG levels with the patients' characteristics and laboratory data were also analyzed.

Results: Significant reduction of the fasting BG, preprandial BG, postprandial BG, and standard deviation (SD) of the 6-point BG levels was
\end{abstract}

S. Terui · R. Akamatsu - M. Arai · T. Okuyama . M. Kyohara · D. Miyashita .

Y. Togashi · Y. Terauchi · J. Shirakawa $(\bowtie)$ Department of Endocrinology and Metabolism, Graduate School of Medicine, Yokohama City University, Yokohama, Japan

e-mail: jshira@gunma-u.ac.jp

R. Inoue $\cdot \mathrm{J}$. Li $\cdot$ T. Tsuno $\cdot \mathrm{J}$. Shirakawa Laboratory of Diabetes and Metabolic Disorders, Institute for Molecular and Cellular Regulation (IMCR), Gunma University, Maebashi, Japan observed on day 1 as compared to day -1 $(P<0.0001)$ and the reduced BG levels were maintained throughout the remaining observation period of 5 days. The baseline serum hemoglobin A1c and glycoalbumin levels were positively correlated with the reduction of the fasting BG. The $\Delta \mathrm{BG}$ levels were not related to the parameters of insulin-secreting capacity. Insulin treatment was positively associated with the reduction of the 6-point BG levels. Patients without cerebrovascular disease and patients without diabetic retinopathy showed greater improvements of the fasting BG and SD of the 6-point BG levels, respectively. Urinary microalbumin level was positively correlated with improvements of the 6-point BG levels. Dulaglutide reduced the BG levels, irrespective of the previously used class of antidiabetic medication(s).

Conclusion: Dulaglutide achieved reduction in glucose level within $24 \mathrm{~h}$ of the first injection. The improvement in the BG levels remained stable for a week in the hospitalized clinical setting.

Keywords: Dulaglutide; Glucagon-like peptide 1 receptor agonist; Type 2 diabetes 


\section{Key Summary Points}

Why carry out this study?

Dulaglutide is a long-acting glucagonlike peptide 1 receptor agonist that is administered once weekly in the treatment of type 2 diabetes

Its long-term effectiveness in reducing the fasting and postprandial blood glucose (BG) levels, hemoglobin A1c (HbA1c) levels, and body weight, with a minimal risk of hypoglycemia has been welldocumented by previous studies; however, the immediate glucose response after the first administration of the drug and factors influencing it still remain unclear

\section{What was learned from the study?}

Dulaglutide achieved reduction in glucose level within $24 \mathrm{~h}$ of the first injection, and the reduced BG levels were stably maintained for at least a week in the hospitalized clinical setting

Dulaglutide was effective even in patients with elevated baseline HbA1c levels, irrespective of the age, body mass index, beta cell function, duration of diabetes, and previously used antidiabetic medications

These results might be useful knowledge for early decision-making on the appropriate treatment regimen for glycemic control in patients with type 2 diabetes

\section{INTRODUCTION}

For patients with diabetes who show elevated serum hemoglobin A1c (HbA1c) levels, improvements of both fasting and postprandial blood glucose (BG) levels are necessary. In regard to glycemic control in the hospital setting, prompt reduction of the $\mathrm{BG}$ can be achieved with strict dietary modification and intensive glycemia control. However, hospitalization for more than a certain length of time is difficult and impractical for young and middleaged patients who are busy at work or school. For elderly patients and patients with physi$\mathrm{cal} /$ mental disabilities, the therapeutic regimen needs to be selected taking into consideration their ability to handle medications and the available support from family and/or social services. Hence, several factors need to be taken into consideration in selecting the appropriate regimen for glycemic control in short-term hospitalized diabetes patients.

Dulaglutide is a long-acting glucagonlike peptide 1 receptor agonist (GLP-1 RA) that is administered once a week for the treatment of type 2 diabetes. It consists of two identical chains, each containing a modified GLP-1 analogue sequence linked to a modified immunoglobulin G4 (IgG4) Fc fragment for protection from dipeptidyl peptidase 4 (DPP4) inactivation and a reduction in renal clearance. This structure slows the clearance rate of the drug, allowing once-weekly administration [1]. The approved dosage of dulaglutide in Japan is $0.75 \mathrm{mg}$ weekly [2].

The long-term effectiveness of the drug in reducing the fasting and postprandial BG levels, serum HbA1c levels, and body weight, with a low risk of hypoglycemia, was well established by the AWARD clinical trials conducted for 26-104 weeks [3-10]. The treatment satisfaction and perceived frequency of hyperglycemia were significantly improved in the dulaglutide as compared to the placebo arm at 26 weeks and as compared to twice-daily exenatide treatment at 26 and 52 weeks in the AWARD-1 trial [11]. In the AWARD-3 trial, although there was no difference in the overall degree of treatment satisfaction between the dulaglutide and metformin arm, a significantly greater reduction in the perceived frequency of hyperglycemia was observed in the dulaglutide arm at 52 weeks [11]. An observational study showed greater adherence to and persistence with dulaglutide treatment as compared to twicedaily or weekly exenatide, lixisenatide, or liraglutide treatment [12]. Similar results were 
reported from comparisons with semaglutide and weekly exenatide [13]. The retrospective analysis of data conducted by the Japan Diabetes Clinical Data Management Study Group revealed that dulaglutide was the most frequently prescribed initial GLP-1 RA (65.7\%) in Japan, and that the persistence rates with the treatment at 6,12 , and 18 months after its initiation were $81.9 \%, 70.7 \%$, and $65.4 \%$, respectively [14]. These rates were higher than those reported for liraglutide, the second most commonly prescribed initial GLP-1 RA (29.1\%), the treatment persistence rates for which were $79.7 \%, 60.0 \%$, and $30.4 \%$ at 6,12 , and 18 months after the treatment initiation [14].

The dulaglutide device is single-dose pen which automatically injects drug by just unlocking and pressing the button without the need for needle attachment. Its simple handling and once-weekly administration relieve the treatment burden. No difference in the frequency of gastrointestinal adverse events was demonstrated between the dulaglutide arm and the exenatide or liraglutide arm in the AWARD1 or AWARD- 6 trials, and the symptoms were mild to moderate in most cases [3, 7]. These merits of dulaglutide appear to be the reason for the higher satisfaction with and good adherence to the drug. In addition, dulaglutide was demonstrated in the REWIND trial to be beneficial for both primary and secondary prevention of cardiovascular events and renal outcomes in middle-aged to elderly patients with type 2 diabetes, showing a broad range of glycemic control $[15,16]$.

Short-term treatment with dulaglutide resulted in a significant reduction of the fasting BG levels at 2 weeks after the first administration in the AWARD- 1 and AWARD-5 trials $[3,6]$. In regard to the pharmacokinetic characteristics of dulaglutide, the maximum plasma concentration is reached at $48 \mathrm{~h}$ after administration and stable plasma concentrations are achieved in 2-4 weeks $[2,17]$. A greater degree of reduction of the HbA1c and fasting BG levels was observed at 6 and 12 months in patients with baseline HbA1c levels of at least $8.5 \%$ $(69 \mathrm{mmol} / \mathrm{mol})$ than in patients with baseline HbA1c levels of less than $8.5 \%(69 \mathrm{mmol} / \mathrm{mol})$ [18]. Another post hoc analysis of the data from
AWARD-1 and AWARD-5 revealed that lower fasting BG levels (less than $142.2 \mathrm{mg} / \mathrm{dL}$ ) at week 2 predicted greater reduction of the HbA1c at week 26 of treatment [19]. Because these studies were focused on the long-term efficacy of dulaglutide, factors influencing the immediate blood glucose responses to dulaglutide treatment have remained unclear. There are only a few reports on the immediate BG responses to dulaglutide administration and no reports of the possible factors associated with the efficacy of the drug because of the limited number of patients [20-22].

In this study, we investigated the timing of initial glucose lowering, in terms of the fasting and postprandial BG levels, and changes in the daily blood glucose fluctuations in response to the first administration of dulaglutide, and explored the factors that affected the efficacy of its first administration among patients with type 2 diabetes who had been hospitalized for the glycemic control.

\section{METHODS}

\section{Participants}

This study was a single-arm, retrospective, and observational analysis of 80 subjects with type 2 diabetes who were hospitalized at the Department of Endocrinology and Metabolism, Yokohama City University Hospital, between January 1, 2016, and August 31, 2020, for glycemic control. All the subjects were at least 20 years of age and were initiated on treatment with dulaglutide $(0.75 \mathrm{mg}$, subcutaneously injected once weekly) for the first time. Patients with serious liver disorder, cancer, mental illness, ketosis, diabetic coma, infection, injury, pancreatic exocrine disorder, endocrinological disorder, or those in a postoperative state were excluded from this study. This study was conducted with the approval of the ethics committee of Yokohama City University Hospital (B191100009). The study protocol was in compliance with the principles outlined in the 1964 Declaration of Helsinki and its later amendments. Written informed consent from the subjects was not required because of the 
anonymized nature of the data collected from the existing medical records. We informed the participants about the objectives, method, research period, and types of data collected in this study, and of their right to refuse participation in the study via a notice put up on the website of Yokohama City University Hospital.

\section{Study Design}

The BG levels were measured daily with a glucometer (Medisafe Fit Smile, Terumo Corporation) before and $2 \mathrm{~h}$ after each meal, at 7:30 $(n=54-80), \quad 10: 30 \quad(n=47-80), \quad 11: 30$ $(n=47-80), \quad 14: 30 \quad(n=43-77), \quad 17: 30$ $(n=46-79)$, and 20:30 $(n=44-78)$ (data collected for 8 days) (Fig. 1). Overnight fasting blood samples and spot urine samples were collected before the start of dulaglutide administration and within 4 days of hospital admission. The 24-h urinary samples for C-peptide and microalbumin measurements were collected within 6 days of hospitalization. The body weight and waist circumference were measured within 3 days of hospitalization. Blood pressure and heart rate measured a day before the start of dulaglutide administration were adopted for the analyses. Administration of DPP4 inhibitors or other GLP-1 RAs was discontinued a day before the first injection of dulaglutide.

Other glucose-lowering medications, including insulin, were continued, with their doses adjusted as needed, except on the 3 days before and after the dulaglutide injection. The primary outcome was the changes in the BG levels at six aforementioned time points (6point BG levels) from the baseline to the day after the administration of dulaglutide. We also analyzed the associations of the changes in the BG levels with the patients' characteristics and laboratory data. HbA1c was measured by highperformance liquid chromatography (HPLC). The estimated glomerular filtration rate (eGFR) was calculated by the modified IDMS-MDRD equation: $194 \times$ serum creatinine $(\mathrm{Cre})^{-1.094-}$ $\times \operatorname{age}^{-0.287}(\times 0.739$ for women). The C-peptide index (CPI) was calculated as (fasting C-peptide immunoreactivity (CPR))/(fasting blood glucose) $\times 100$. The FIB-4 index was calculated as the serum aspartate aminotransferase level (AST) $(\mathrm{IU} / \mathrm{L}) \times$ age/platelet $\left(10^{9} /\right.$ L) $\times \sqrt{ }$ serum alanine aminotransferase level (ALT) (IU/L).

\section{Statistical Analysis}

The 6-point BG levels of a day before (day - 1) and a day after (day 1) the first dulaglutide

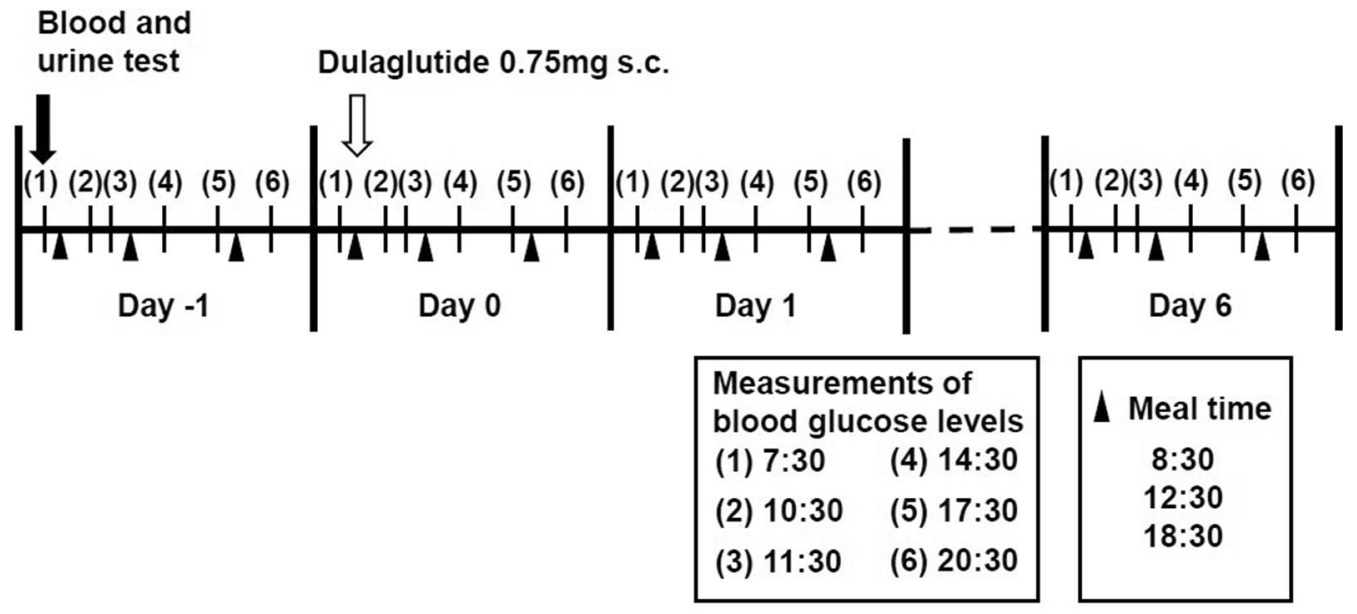

Fig. 1 Study design. (1) to (6) indicate the timing of glucose levels measurements at 7:30, 10:30, 11:30, 14:30, 17:30, and 20:30, respectively. The triangles show meal times; breakfast at 8:30, lunch at 12:30, and dinner at 18:30. Dulaglutide was injected just before breakfast on day 0 
administration were expressed as arithmetic mean \pm standard deviation (SD) and evaluated by Wilcoxon signed rank test. The fasting, preprandial, and postprandial BG levels, and the SD of the 6-point BG levels were expressed as median values [25th-75th percentile] and the changes were statistically evaluated by the Wilcoxon signed rank test. The changes $(\Delta)$ of the fasting BG levels, 2-h post breakfast BG levels, mean of the 6-point BG levels, and SD of the BG levels, between day -1 and day 1 were expressed as median values except for these changes regarding sex which were expressed as mean values. Correlations between the $\Delta \mathrm{BG}$ levels and continuous variables were evaluated by simple linear regression analysis. Associations between the $\Delta \mathrm{BG}$ levels and categorical variables were evaluated by the Mann-Whitney $U$ test. In all tests, $P<0.05$ was considered as being indicative of significance. All the statistical analyses were conducted using JMP Pro version 15.0.0 (SAS Institute Inc., NC, USA).

Table 1 Baseline patient characteristics

\begin{tabular}{ll}
\hline Baseline characteristics & Values $(\boldsymbol{N}=\mathbf{8 0})$ \\
\hline Age $($ years $)$ & $72[60-80]$ \\
Sex $($ male/female $)$ & $41 / 39$ \\
BMI $\left(\mathrm{kg} / \mathrm{m}^{2}\right)$ & $26.6[23.4-29.8]$ \\
Prior use of GLP-1 RAs & 10 \\
Prior use of DPP4 inhibitors & 56 \\
HbA1c $(\%)(\mathrm{mmol} / \mathrm{mol})$ & $9.1[8.0-10.1](75$ \\
& $\quad[63-86])$ \\
FPG $(\mathrm{mg} / \mathrm{dL})$ & $158[136-193]$ \\
eGFR $\left(\mathrm{mL} / \mathrm{min} / 1.73 \mathrm{~m}^{2}\right)$ & $64.6[50.7-86.1]$ \\
Urinary CPR $(\mu \mathrm{gg} / \mathrm{day})$ & $73.4[40.0-119.8]$ \\
Fasting CPR $(\mathrm{ng} / \mathrm{mL})$ & $2.6[1.8-4.0]$ \\
\hline
\end{tabular}

All data shown are median values [25th-75th percentile], except sex and prior use of medication, which are shown in numbers

$B M I$ body mass index, $C P R$ C-peptide immunoreactivity, $D P P 4$ dipeptidyl peptidase 4, FPG fasting plasma glucose, GLP-1 RAs glucagon-like peptide 1 receptor agonists

\section{RESULTS}

\section{Baseline Characteristics}

The baseline characteristics of the 80 hospitalized patients with type 2 diabetes enrolled in this study are shown in Table 1 . The median age was 72 (60-80) years, the median body mass index (BMI) was $26.6(23.4-29.8) \mathrm{kg} / \mathrm{m}^{2}$, the median HbA1c was 9.1 (8.0-10.1)\% (75 (63-86) $\mathrm{mmol} / \mathrm{mol}$ ), and the median urinary CPR was $73.4(40.0-119.8) \mu \mathrm{g} /$ day. The proportion of patients with a prior history of use of other GLP1 RAs and DPP4 inhibitors was $12.5 \%$ and $70 \%$, respectively.

\section{Glucose-Lowering Effect in the Early Phase After Administration of Dulaglutide}

To examine the short-term effects of dulaglutide on the BG levels, we compared the 6-point BG levels at the baseline (day - 1) with those on the day after the first administration of dulaglutide at the dose of $0.75 \mathrm{mg}$ (day 1) (Fig. 2). Both fasting and postprandial BG levels were significantly lower on day 1 as compared to day $-1 \quad(P<0.0001$, except for the postlunch values; $P<0.01$ ). Figure 3 shows the blood glucose excursions expressed as the SD of the 6-point BG levels, which were also lower on day 1 than on day $-1 \quad(P<0.0001)$. These results indicate that dulaglutide effectively

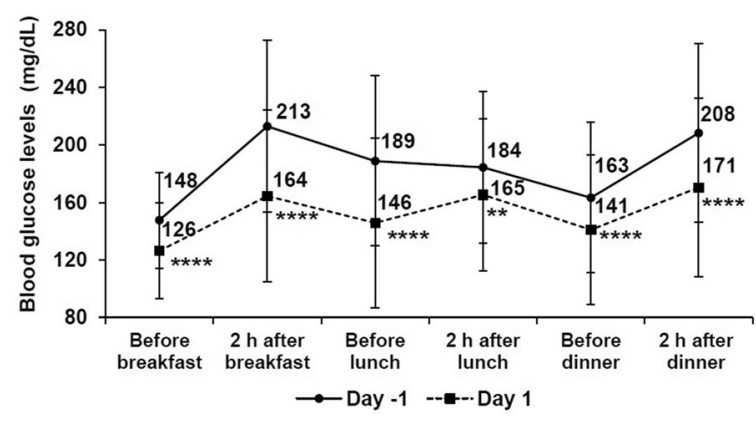

Fig. 2 Six-point BG levels at the baseline $($ day -1$)$ and on the day after the first dulaglutide administration (day 1). Day 0 indicates the day of administration of dulaglutide. BG levels, blood glucose levels. ${ }^{* *} P<0.01$ vs. day $-1,{ }^{* * * *} P<0.0001$ vs. day -1 . All data shown are the arithmetic means $\pm S D$ 


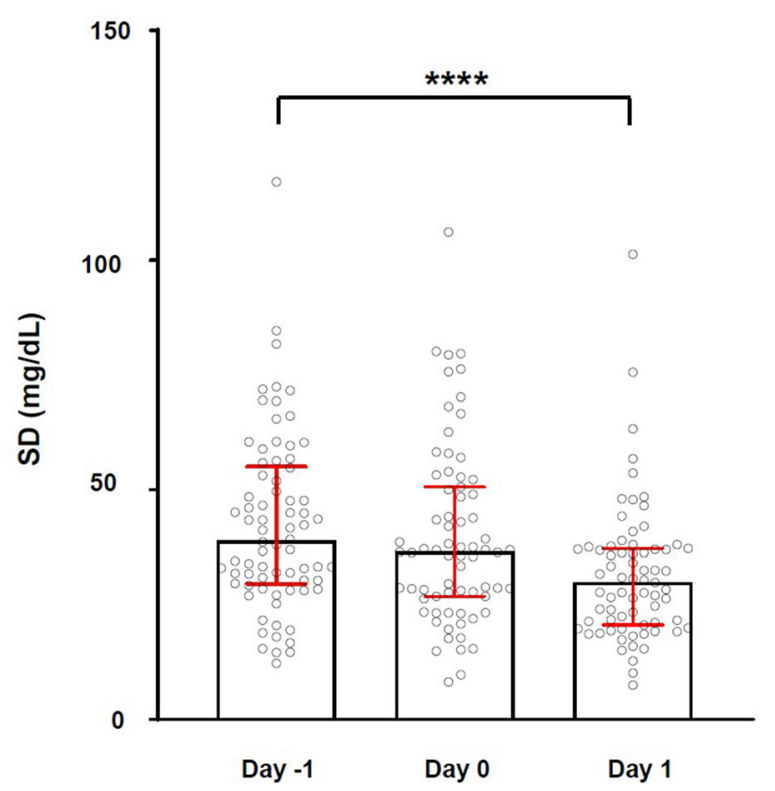

Fig. 3 Changes in the blood glucose excursions, expressed as the $\mathrm{SD}$ of the 6-point $\mathrm{BG}$ levels, from the baseline $($ day -1$)$ to the day after the first administration of dulaglutide (day 1 ). Day 0 indicates the day of administration of dulaglutide. SD, standard deviation of the 6-point blood glucose levels. ${ }^{* * * *} P<0.0001$ vs. day -1 . All data shown are the median values $\pm(25-75 \%)$

decreased the BG levels and daily blood glucose fluctuations by the day after the first injection in patients with poorly controlled type 2 diabetes, i.e., even before the reported time at which the maximum concentration of the drug is reached ( $48 \mathrm{~h}$ after administration). The reductions in the fasting, preprandial, and postprandial BG levels, and in the SD of the 6-point BG levels were maintained stably for the rest of the observation period (5 days, $P<0.0001$, except for the SD on day 6; $P<0.001$ ) (Fig. 4).

Six patients presented mild nausea and slightly decreased appetite during 2-4 days after dulaglutide administration. Two of them also claimed constipation or mild abdominal pain. The proportion of adverse events was less than previous studies in which nausea was observed ranging from $7.7 \%$ to $16 \%[3-6,10]$. All the patients recovered from aforementioned adverse events spontaneously in a few days. a
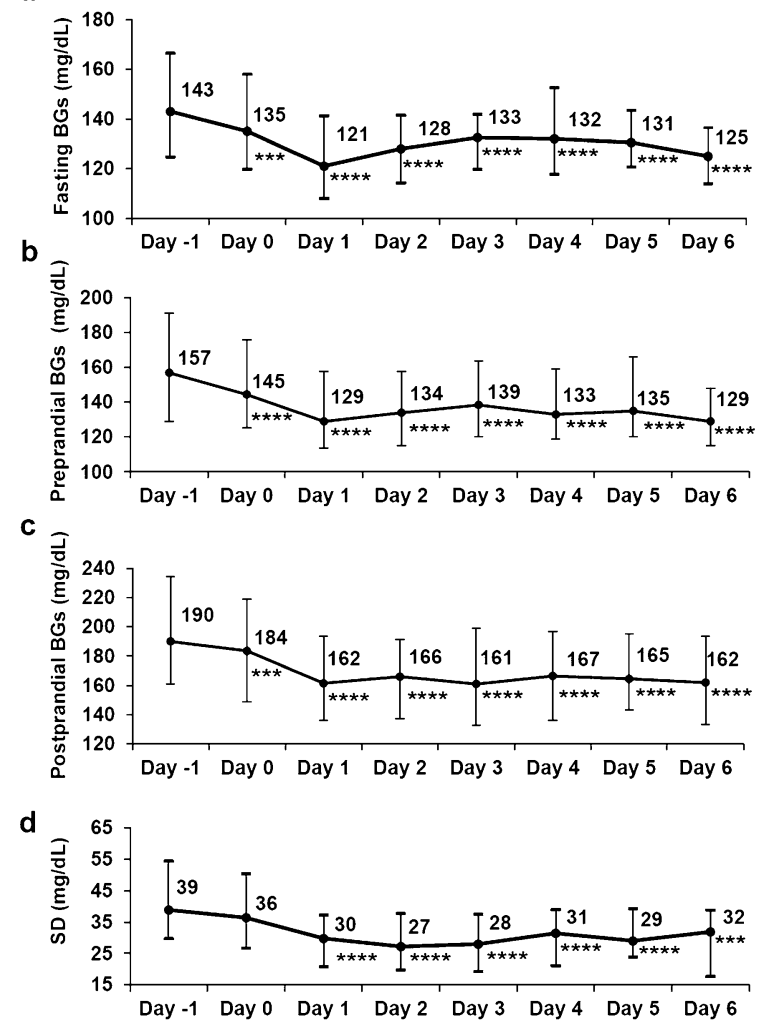

Fig. 4 Changes in the fasting, preprandial, postprandial, and in the SD of the 6-point BG levels. Day 0 indicates the day of administration of dulaglutide. BG levels, blood glucose levels; SD, standard deviation. a Fasting blood glucose levels, b Preprandial blood glucose levels, c Postprandial blood glucose levels, d Standard deviation. ${ }^{* * *} P<0.001$ vs. day $-1,{ }^{* * * *} P<0.0001$ vs. day -1 . All data show are the median values $\pm(25-75 \%)$

\section{Factors Associated with the Blood Glucose- Lowering Effect of Dulaglutide on the Day After Administration}

Next, we explored the factors that were associated with the reduction of the BG levels in the patients treated with dulaglutide between day -1 and day 1 (Tables 2 and 3). There was no significant association of the age, sex, or BMI with the glucose-lowering effect of dulaglutide. A positive correlation was observed between higher HbA1c values at the baseline and the change in the $(\Delta)$ fasting BG $(r=0.461$, $P<0.001)$. The serum glycoalbumin (GA) level at the baseline was also positively correlated 
Table 2 Correlations of the changes in the blood glucose levels with the patient characteristics and laboratory data

\begin{tabular}{|c|c|c|c|c|c|c|c|c|}
\hline \multirow[t]{2}{*}{ Variable } & \multicolumn{2}{|c|}{$\begin{array}{l}\Delta \text { fasting BG level } \\
(\mathrm{mg} / \mathrm{dL})\end{array}$} & \multicolumn{2}{|c|}{$\begin{array}{l}\Delta \text { 2-h post-breakfast } \\
\text { BG level }(\mathrm{mg} / \mathrm{dL})\end{array}$} & \multicolumn{2}{|c|}{$\begin{array}{l}\Delta \text { mean value of } \\
\text { 6-point BG levels } \\
(\mathrm{mg} / \mathrm{dL})\end{array}$} & \multicolumn{2}{|c|}{$\begin{array}{l}\Delta \text { SD of 6-point BG } \\
\text { levels }(\mathrm{mg} / \mathrm{dL})\end{array}$} \\
\hline & $r$ & $P$ value & $r$ & $P$ value & $r$ & $P$ value & $r$ & $P$ value \\
\hline Age & 0.041 & 0.716 & 0.025 & 0.823 & -0.076 & 0.545 & 0.018 & 0.884 \\
\hline BMI & -0.167 & 0.138 & -0.111 & 0.033 & -0.043 & 0.732 & 0.034 & 0.790 \\
\hline Waist circumference & -0.218 & 0.062 & -0.152 & 0.201 & -0.095 & 0.469 & -0.156 & 0.234 \\
\hline Duration of diabetes & -0.016 & 0.159 & -0.003 & 0.979 & -0.135 & 0.296 & 0.071 & 0.583 \\
\hline Systolic BP & 0.050 & 0.658 & 0.107 & 0.351 & 0.041 & 0.744 & 0.103 & 0.414 \\
\hline Diastolic BP & -0.114 & 0.315 & -0.149 & 0.188 & -0.101 & 0.422 & -0.081 & 0.522 \\
\hline Heart rate & -0.035 & 0.758 & -0.184 & 0.101 & -0.117 & 0.352 & -0.299 & $0.016^{*}$ \\
\hline HbAlc & 0.461 & $<0.001^{* * *}$ & 0.132 & 0.244 & 0.203 & 0.105 & -0.018 & 0.885 \\
\hline eGFR & 0.137 & 0.224 & -0.044 & 0.699 & 0.074 & 0.561 & -0.125 & 0.322 \\
\hline Urinary CPR & -0.142 & 0.472 & -0.045 & 0.819 & 0.022 & 0.918 & -0.201 & 0.336 \\
\hline Fasting CPR & 0.076 & 0.508 & 0.102 & 0.369 & 0.048 & 0.707 & 0.068 & 0.591 \\
\hline WBC & 0.039 & 0.733 & 0.129 & 0.254 & 0.066 & 0.601 & 0.084 & 0.503 \\
\hline $\mathrm{RBC}$ & -0.124 & 0.271 & -0.154 & 0.170 & -0.203 & 0.105 & -0.210 & 0.093 \\
\hline $\mathrm{Hb}$ & -0.112 & 0.321 & -0.109 & 0.337 & -0.140 & 0.265 & -0.058 & 0.647 \\
\hline Plt & 0.022 & 0.847 & -0.218 & 0.052 & -0.180 & 0.152 & -0.207 & 0.098 \\
\hline TP & -0.013 & 0.906 & -0.279 & $0.012^{*}$ & -0.247 & $0.047^{*}$ & -0.204 & 0.102 \\
\hline Alb & -0.013 & 0.910 & -0.137 & 0.226 & -0.113 & 0.369 & -0.088 & 0.487 \\
\hline AST & 0.033 & 0.774 & 0.158 & 0.162 & 0.052 & 0.679 & 0.135 & 0.283 \\
\hline ALT & 0.052 & 0.645 & 0.134 & 0.236 & 0.082 & 0.518 & 0.147 & 0.244 \\
\hline$\gamma$-GTP & 0.132 & 0.244 & 0.055 & 0.628 & 0.025 & 0.844 & 0.021 & 0.870 \\
\hline FIB-4 index & 0.182 & 0.106 & 0.225 & $0.045^{*}$ & 0.215 & 0.085 & 0.131 & 0.300 \\
\hline ALP & 0.303 & $0.006^{* *}$ & 0.249 & $0.026^{*}$ & 0.354 & $0.004^{* *}$ & 0.005 & 0.970 \\
\hline LDH & 0.076 & 0.500 & 0.240 & $0.032^{*}$ & 0.209 & 0.094 & 0.115 & 0.360 \\
\hline ChE & -0.008 & 0.458 & -0.198 & 0.079 & -0.160 & 0.195 & -0.114 & 0.365 \\
\hline AMY & 0.083 & 0.469 & -0.003 & 0.976 & -0.123 & 0.331 & -0.216 & 0.086 \\
\hline BUN & -0.167 & 0.138 & -0.020 & 0.861 & -0.133 & 0.292 & 0.020 & 0.872 \\
\hline Cre & -0.074 & 0.514 & 0.058 & 0.607 & -0.004 & 0.974 & 0.204 & 0.103 \\
\hline UA & -0.226 & $0.043^{*}$ & -0.069 & 0.541 & -0.157 & 0.211 & 0.074 & 0.560 \\
\hline $\mathrm{Na}$ & -0.407 & $<0.001^{* * *}$ & -0.225 & $0.045^{*}$ & -0.256 & $0.039^{*}$ & -0.046 & 0.714 \\
\hline $\mathrm{K}$ & 0.106 & 0.348 & -0.216 & 0.054 & -0.125 & 0.330 & -0.102 & 0.419 \\
\hline
\end{tabular}


Table 2 continued

\begin{tabular}{|c|c|c|c|c|c|c|c|c|}
\hline \multirow[t]{2}{*}{ Variable } & \multicolumn{2}{|c|}{$\begin{array}{l}\Delta \text { fasting BG level } \\
(\mathrm{mg} / \mathrm{dL})\end{array}$} & \multicolumn{2}{|c|}{$\begin{array}{l}\Delta \text { 2-h post-breakfast } \\
\text { BG level }(\mathrm{mg} / \mathrm{dL})\end{array}$} & \multicolumn{2}{|c|}{$\begin{array}{l}\Delta \text { mean value of } \\
\text { 6-point BG levels } \\
(\mathrm{mg} / \mathrm{dL})\end{array}$} & \multicolumn{2}{|c|}{$\begin{array}{l}\Delta S D \text { of 6-point BG } \\
\text { levels }(\mathrm{mg} / \mathrm{dL})\end{array}$} \\
\hline & $r$ & $P$ value & $r$ & $P$ value & $r$ & $P$ value & $r$ & $P$ value \\
\hline $\mathrm{Cl}$ & -0.313 & $0.005^{* *}$ & -0.077 & 0.497 & -0.152 & 0.225 & 0.070 & 0.581 \\
\hline $\mathrm{Ca}$ & 0.218 & 0.052 & -0.035 & 0.757 & 0.08 & 0.888 & -0.030 & 0.812 \\
\hline $\mathrm{P}$ & 0.026 & 0.818 & -0.065 & 0.567 & 0.009 & 0.944 & -0.153 & 0.223 \\
\hline $\mathrm{Mg}$ & 0.086 & 0.471 & -0.106 & 0.371 & -0.058 & 0.661 & -0.218 & 0.095 \\
\hline Ferritin & 0.141 & 0.217 & 0.100 & 0.382 & 0.119 & 0.354 & 0.208 & 0.102 \\
\hline T-Bil & -0.261 & $0.020^{*}$ & 0.141 & 0.241 & 0.024 & 0.854 & 0.199 & 0.115 \\
\hline CRP & -0.036 & 0.754 & 0.113 & 0.320 & 0.027 & 0.833 & 0.200 & 0.113 \\
\hline T-Chol & 0.121 & 0.284 & 0.105 & 0.354 & 0.091 & 0.471 & -0.033 & 0.792 \\
\hline TG & -0.046 & 0.687 & 0.203 & 0.071 & 0.084 & 0.506 & 0.224 & 0.072 \\
\hline HDL-C & 0.082 & 0.468 & 0.012 & 0.919 & -0.011 & 0.930 & -0.246 & $0.048^{*}$ \\
\hline LDL-C & 0.110 & 0.329 & 0.051 & 0.652 & 0.074 & 0.558 & -0.039 & 0.558 \\
\hline TSH & 0.019 & 0.879 & 0.022 & 0.861 & 0.004 & 0.976 & 0.113 & 0.412 \\
\hline FT4 & 0.004 & 0.974 & -0.267 & $0.028^{*}$ & 0.024 & 0.861 & -0.004 & 0.977 \\
\hline GA & 0.436 & $<0.001^{* * *}$ & 0.118 & 0.302 & 0.177 & 0.161 & -0.081 & 0.524 \\
\hline CPI & -0.086 & 0.443 & 0.040 & 0.730 & -0.066 & 0.606 & 0.028 & 0.826 \\
\hline Urinary microalbumin & 0.120 & 0.321 & 0.046 & 0.704 & 0.277 & $0.037^{*}$ & 0.191 & 0.154 \\
\hline
\end{tabular}

$\Delta$, change from the baseline, calculated as the value on day -1 minus the value on day $1 . r$, coefficient of correlation $A L T$ serum alanine aminotransferase, $A l b$ serum albumin, $A M Y$ serum amylase, $A L P$ serum alkaline phosphatase, $A S T$ serum aspartate aminotransferase, $B G$ blood glucose, $B M I$ body mass index, $B P$ blood pressure, $B U N$ blood urea nitrogen, $C a$ serum calcium, $C h E$ serum cholinesterase, $C l$ serum chloride, $C P I$ serum C-peptide index, CPR C-peptide immunoreactivity, $C r e$ serum creatinine, $C R P$ serum C-reactive protein, FT4 serum free T4, $G A$ serum glycoalbumin, $H b$ serum hemoglobin, $H D L-C$ serum high-density lipoprotein cholesterol, $K$ serum potassium, $L D H$ serum lactate dehydrogenase, $L D L-C$ serum low density lipoprotein cholesterol, $M g$ serum magnesium, $N a$ serum sodium, $P$ serum phosphorus, Plt platelet, $S D$ standard deviation, $T$-Bil serum total bilirubin, T-Chol serum total cholesterol, $T G$ serum triglycerides, $T P$ serum total protein, $T S H$ serum thyroid-stimulating hormone, $U A$ serum uric acid, $W B C$ white blood cell, $R B C$ red blood cell, $\gamma$-GTP serum $\gamma$-glutamyl transpeptidase

${ }^{*} P<0.05,{ }^{* *} P<0.01,{ }^{* * *} P<0.001$

with the $\Delta$ fasting BG $(r=0.436, P<0.001)$. No correlations were observed between the changes in the BG levels and the parameters related to the insulin secretory capacity (fasting CPR, urinary CPR, and CPI).

The $\Delta \mathrm{BG}$ levels showed no correlations with duration of diabetes. In regard to the influence of diabetic complications, patients without a history of cerebrovascular disease and without a history of diabetic retinopathy showed a greater $\Delta$ fasting BG and $\Delta \mathrm{SD}$ of the 6-point BG levels $(P<0.05)$, respectively. Although no correlation was observed between the presence of diabetic nephropathy and the $\triangle B G$ levels, the 
Table 3 Differential changes in the blood glucose levels depending on the patient characteristics/diabetic complications

\begin{tabular}{|c|c|c|c|c|c|c|c|c|c|c|c|c|}
\hline & \multicolumn{3}{|c|}{$\begin{array}{l}\text { Fasting BG level } \\
(\mathrm{mg} / \mathrm{dL})\end{array}$} & \multicolumn{3}{|c|}{$\begin{array}{l}\text { 2-h post-breakfast } \\
\text { BG level }(\mathrm{mg} / \mathrm{dL})\end{array}$} & \multicolumn{3}{|c|}{$\begin{array}{l}\text { Mean value of } \\
\text { 6-point BG levels } \\
(\mathrm{mg} / \mathrm{dL})\end{array}$} & \multicolumn{3}{|c|}{$\begin{array}{l}\text { SD of 6-point BG } \\
\text { levels }(\mathrm{mg} / \mathrm{dL})\end{array}$} \\
\hline & \multicolumn{2}{|l|}{$\Delta$} & \multirow[t]{2}{*}{$P$ value } & \multicolumn{2}{|l|}{$\Delta$} & \multirow[t]{2}{*}{$P$ value } & \multicolumn{2}{|l|}{$\bar{\Delta}$} & \multirow[t]{2}{*}{$P$ value } & \multicolumn{2}{|l|}{$\bar{\Delta}$} & \multirow[t]{2}{*}{$P$ value } \\
\hline & + & - & & + & - & & + & - & & + & - & \\
\hline $\operatorname{Sex}^{\dagger}$ & 20.0 & 22.9 & 0.878 & 46.3 & 51.0 & 0.996 & 29.3 & 37.3 & 0.688 & 11.3 & 6.6 & 0.418 \\
\hline Smoking history & 19.0 & 16.5 & 0.939 & 64.0 & 35.0 & $0.019^{*}$ & 32.9 & 22.8 & 0.056 & 10.0 & 6.8 & 0.063 \\
\hline Drinking history & 19.0 & 16.5 & 0.960 & 48.0 & 44.0 & 0.774 & 32.8 & 27.8 & 0.881 & 12.3 & 7.1 & 0.072 \\
\hline Family history of diabetes & 16.5 & 19.0 & 0.917 & 52.5 & 34.0 & 0.447 & 28.4 & 29.0 & 0.440 & 9.5 & 8.2 & 0.373 \\
\hline Obesity & 19.0 & 10.0 & 0.566 & 45.0 & 37.0 & 0.662 & 29.0 & 18.3 & 0.217 & 9.3 & 6.5 & 0.501 \\
\hline Hyperlipidemia & 16.0 & 20.0 & 0.818 & 49.0 & 33.0 & 0.234 & 29.5 & 20.8 & 0.224 & 9.2 & 8.7 & 0.427 \\
\hline Hypertension & 16.5 & 24.5 & 0.725 & 47.0 & 35.5 & 0.576 & 28.7 & 30.5 & 0.719 & 9.2 & 8.7 & 0.604 \\
\hline Ischemic cardiac disease & 10.0 & 20.0 & 0.081 & 41.0 & 47.0 & 0.445 & 23.3 & 29.0 & 0.331 & 11.6 & 8.2 & 0.451 \\
\hline Cerebrovascular disease & 11.0 & 23.0 & $0.017^{*}$ & 41.0 & 47.0 & 0.279 & 22.3 & 29.5 & 0.133 & 8.8 & 9.2 & 0.843 \\
\hline Peripheral arterial disease & 7.5 & 17.0 & 0.172 & 52.5 & 43.0 & 0.930 & 27.5 & 28.8 & 0.762 & 13.7 & 9.3 & 0.742 \\
\hline Diabetic retinopathy & 13.0 & 18.5 & 0.444 & 30.5 & 54.0 & 0.066 & 23.7 & 29.1 & 0.194 & 3.2 & 9.8 & $0.040^{*}$ \\
\hline Diabetic nephropathy & 14.0 & 19.0 & 0.944 & 49.0 & 39.0 & 0.216 & 32.5 & 28.0 & 0.347 & 12.6 & 7.6 & 0.252 \\
\hline Diabetic peripheral neuropathy & 20.0 & 11.5 & 0.717 & 48.0 & 37.0 & 0.741 & 28.4 & 29.3 & 0.685 & 7.3 & 9.9 & 0.128 \\
\hline Diabetic autonomic neuropathy & 19.0 & 17.5 & 0.950 & 43.0 & 59.5 & 0.351 & 26.2 & 32.9 & 0.278 & 8.2 & 9.3 & 0.292 \\
\hline
\end{tabular}

Data shown are the median values, unless indicated otherwise

$B G$ blood glucose, $S D$ standard deviation

${ }^{*} P<0.05$

$\dagger$ Data shown are the mean values. + Data of patients with factors or male; - Data of patients without factors or female. $\Delta$, change from the baseline, calculated as value on day -1 minus value on day 1

urinary microalbumin level was positively correlated with the $\Delta$ mean of the 6-point BG levels $(r=0.277, P<0.05)$. The FIB-4 index was positively correlated with the $\Delta$ post-breakfast BG $(r=0.225, \quad P<0.05)$. Serum alkaline phosphatase (ALP) was positively correlated with the $\Delta$ fasting BG $(r=0.303, P<0.01), \Delta$ post-breakfast BG $(r=0.249, P<0.05)$, and $\Delta$ mean of the 6-point BG levels $(r=0.354, P<0.01)$. Serum total bilirubin (T-Bil) was negatively correlated with the $\Delta$ fasting BG $(r=-0.261, P<0.05)$. Serum lactate dehydrogenase (LDH) was positively correlated with the $\Delta$ post-breakfast BG levels $(r=0.240, P<0.05)$. Other factors associated with the $\Delta$ BG levels in the present study include the serum sodium $(\mathrm{Na})$, serum chloride
(Cl), serum uric acid (UA), high-density lipoprotein cholesterol (HDL-C), serum free T4 (FT4), serum total protein (TP), heart rate, and history of smoking (Tables 2 and 3).

Association between the previously used antidiabetic agents and the changes in the BG levels between day -1 and day 1 were also analyzed in the patients started on dulaglutide treatment (Table 4). A total of 10 patients received daily GLP-1 RA treatment prior to the start of dulaglutide treatment in this study, including liraglutide in 8 patients, exenatide in 1 patient, and lixisenatide in 1 patient. There was no significant difference in the $\Delta$ fasting BG or $\Delta$ post-breakfast BG between the patients who had/had not previously received 
Table 4 Influence of the previously used class of glucose-lowering drugs on the changes in the blood glucose levels observed after dulaglutide administration

\begin{tabular}{|c|c|c|c|c|c|c|c|c|c|c|c|c|c|}
\hline & \multirow[t]{3}{*}{$\begin{array}{l}\text { Number } \\
\text { of cases }\end{array}$} & \multicolumn{3}{|c|}{$\begin{array}{l}\text { Fasting BG level } \\
(\mathrm{mg} / \mathrm{dL})\end{array}$} & \multicolumn{3}{|c|}{$\begin{array}{l}\text { 2-h post-breakfast } \\
\text { BG level }(\mathrm{mg} / \mathrm{dL})\end{array}$} & \multicolumn{3}{|c|}{$\begin{array}{l}\text { Mean value of } \\
\text { 6-point BG levels } \\
(\mathrm{mg} / \mathrm{dL})\end{array}$} & \multicolumn{3}{|c|}{$\begin{array}{l}\text { SD of 6-point BG } \\
\text { levels }(\mathrm{mg} / \mathrm{dL})\end{array}$} \\
\hline & & \multicolumn{2}{|l|}{$\bar{\Delta}$} & \multirow[t]{2}{*}{$P$ value } & \multicolumn{2}{|l|}{$\bar{\Delta}$} & \multirow[t]{2}{*}{$\overline{P \text { value }}$} & \multicolumn{2}{|l|}{$\bar{\Delta}$} & \multirow[t]{2}{*}{$P$ value } & \multicolumn{2}{|l|}{$\bar{\Delta}$} & \multirow[t]{2}{*}{$P$ value } \\
\hline & & + & - & & + & - & & + & - & & + & - & \\
\hline DPP4 inhibitors & 56 & 17.5 & 16.5 & 0.372 & 47.0 & 32.5 & 0.299 & 29.0 & 26.7 & 0.235 & 9.4 & 7.2 & 0.134 \\
\hline Metformin & 33 & 17.0 & 19.0 & 0.699 & 37.0 & 49.0 & 0.206 & 19.8 & 32.9 & 0.138 & 8.2 & 9.3 & 0.868 \\
\hline Thiazolidinediones & 6 & 18.0 & 17.0 & 0.694 & 0.5 & 48.0 & $0.020^{*}$ & 22.8 & 28.8 & 0.396 & 3.7 & 9.3 & 0.172 \\
\hline Sulfonylureas & 19 & 19.0 & 16.0 & 0.439 & 45.0 & 43.0 & 0.429 & 35.3 & 28.2 & 0.537 & 6.5 & 9.3 & 0.432 \\
\hline$\alpha$-GIs & 13 & 11.0 & 19.0 & 0.351 & 49.0 & 43.0 & 0.850 & 14.8 & 29.3 & 0.219 & 4.0 & 9.3 & 0.639 \\
\hline GLP-1 RAs & 10 & & & & & & & & & & & & \\
\hline Liraglutide & 8 & 9.0 & 19.0 & 0.382 & 15.0 & 47.0 & 0.071 & & & & & & \\
\hline Exenatide & 1 & & & & & & & & & & & & \\
\hline Lixisenatide & 1 & & & & & & & & & & & & \\
\hline Glinide & 10 & 10.5 & 20.0 & 0.066 & 25.5 & 49.0 & 0.093 & 18.3 & 29.4 & 0.175 & 4.5 & 9.3 & 0.193 \\
\hline SGLT2 inhibitor & 18 & 10.5 & 19.0 & 0.242 & 35.0 & 52.5 & 0.079 & 25.8 & 30.6 & 0.279 & 4.5 & 9.6 & 0.121 \\
\hline Insulin & 42 & 30.0 & 13.0 & $0.022^{*}$ & 52.0 & 37.5 & 0.071 & 32.8 & 22.8 & $0.029^{*}$ & 10.0 & 5.4 & 0.183 \\
\hline $\begin{array}{l}\text { Rapid-acting } \\
\text { insulin }\end{array}$ & 28 & 30.5 & 13.0 & $0.011^{*}$ & 52.0 & 39.5 & 0.112 & 31.2 & 23.3 & $0.035^{*}$ & 9.4 & 7.3 & 0.327 \\
\hline $\begin{array}{l}\text { Long-acting } \\
\text { insulin }\end{array}$ & 38 & 32.0 & 10.5 & $0.001^{* *}$ & 39.5 & 37.5 & $0.039^{*}$ & 33.3 & 22.8 & $0.011^{*}$ & 10.0 & 5.4 & 0.150 \\
\hline Premixed insulin & 2 & & & & & & & & & & & & \\
\hline
\end{tabular}

Data shown are the median values. + Data of patients with factors; - Data of patients without factors. $\Delta$, change from the baseline, calculated as value on day -1 minus value on day 1

$\alpha$-GI alpha-glucosidase inhibitor, $B G$ blood glucose, DPP4 dipeptidyl peptidase 4, GLP-1 RAs glucagon-like peptide 1 receptor agonists, $S G L T 2$ sodium glucose co-transporter 2, $S D$ standard deviation

${ }^{*} P<0.05,{ }^{* *} P<0.01$

liraglutide. A total of 56 patients had received treatment with DPP4 inhibitors prior to the start of dulaglutide treatment. The BG levels and SD of the 6-point BG levels decreased significantly by a day after dulaglutide administration irrespective of prior use of DPP4 inhibitors. The degree of the reduction in $B G$ levels was unaffected by the discontinuation of DPP4 inhibitors. Metformin, sulfonylureas, glinides, and sodium glucose co-transporter 2 (SGLT2) inhibitors were not necessarily discontinued, but these medications seemed to have no influence on the changes in the BG levels elicited by dulaglutide. The significant reductions in BG levels were also observed irrespective of the use of thiazolidinediones, with smaller $\Delta$ post-breakfast BG levels in the patients taking that class of drug $(P<0.05)$. 
Table 5 Factors associated with the glucose-lowering effects of dulaglutide

\begin{tabular}{|c|c|c|c|c|}
\hline & $\begin{array}{l}\Delta \text { fasting BG } \\
\text { level }(\mathrm{mg} / \mathrm{dL})\end{array}$ & $\begin{array}{l}\Delta \text { 2-h post-breakfast } \\
\text { BG level }(\mathrm{mg} / \mathrm{dL})\end{array}$ & $\begin{array}{l}\Delta \text { mean value of 6-point } \\
\text { BG levels }(\mathrm{mg} / \mathrm{dL})\end{array}$ & $\begin{array}{l}\Delta \text { SD of 6-point BG } \\
\text { levels }(\mathrm{mg} / \mathrm{dL})\end{array}$ \\
\hline Heart rate & & & & - \\
\hline HbAlc & + & & & \\
\hline TP & & - & - & \\
\hline UA & - & & & \\
\hline FIB-4 index & & + & & \\
\hline ALP & + & + & + & \\
\hline T-Bil & - & & & \\
\hline LDH & & + & & \\
\hline HDL-C & & & & - \\
\hline $\mathrm{Na}$ & - & - & - & \\
\hline $\mathrm{Cl}$ & - & & & \\
\hline FT4 & & - & & \\
\hline GA & + & & & \\
\hline $\begin{array}{l}\text { Urinary } \\
\text { microalbumin }\end{array}$ & & & + & \\
\hline Smoking & & + & & \\
\hline $\begin{array}{l}\text { Cerebrovascular } \\
\text { disease* }\end{array}$ & - & & & \\
\hline $\begin{array}{l}\text { Diabetic } \\
\text { retinopathy* }\end{array}$ & & & & - \\
\hline \multicolumn{5}{|c|}{ Previously used class of glucose-lowering medication } \\
\hline Thiazolidinedione* & & - & & \\
\hline Insulin* & + & & + & \\
\hline $\begin{array}{l}\text { Rapid-acting } \\
\text { insulin* }\end{array}$ & + & & + & \\
\hline $\begin{array}{l}\text { Long-acting } \\
\text { insulin* }\end{array}$ & + & + & + & \\
\hline
\end{tabular}

+ positive correlation, - negative correlation except for factors marked with ${ }^{*}$. For factors marked with ${ }^{*}$, + indicates a greater glucose-lowering effect when the factor is present, and - indicates a greater glucose-lowering effects when the factor is absent

$A L P$ alkaline phosphatase, $B G$ blood glucose, $C l$ serum chloride, $F T 4$ serum free T4, $G A$ serum glycoalbumin, $H D L-C$ serum high-density lipoprotein cholesterol, $L D H$ serum lactate dehydrogenase, $N a$ serum sodium, $S D$ standard deviation, $T$-Bil serum total bilirubin, $T P$ serum total protein, $U A$ serum uric acid 
Patients with prior history of insulin use also showed an improved glycemia profile in the early phase after the start of dulaglutide treatment. Both patients who were receiving rapidand long-acting insulin preparations showed a higher $\Delta$ fasting BG $(P<0.05$ and $P<0.01$, respectively) and $\Delta$ mean of the 6-point BG levels ( $P<0.05$ for both) compared to patients who had not received insulin treatment. Patients receiving long-acting insulin also showed a higher $\Delta$ post-breakfast BG $(P<0.05)$ compared to patients who had not received treatment with long-acting insulin. From these outcomes, it would be reasonable to conclude that significant decrease of the BG levels is observed immediately after the first administration of dulaglutide, irrespective of the class of glucose-lowering medications used previously in the patients. A summary of the factors associated with the glucose-lowering effects of dulaglutide is shown in Table 5.

\section{DISCUSSION}

In this study, we assessed the timing of onset of the glucose-lowering effect of dulaglutide after its first injection in patients with type 2 diabetes in a hospital setting, and analyzed the factors that were associated with the glucose-lowering effect of dulaglutide observed on day 1 (a day after the first administration of dulaglutide) as compared to day - 1 (baseline, a day before the first administration of dulaglutide).

The fasting and postprandial BG levels, mean of the 6-point BG levels, as well as the daily blood glucose fluctuations, measured as the SD of the 6-point BG levels, decreased significantly by day 1 after dulaglutide administration, as compared to day -1 , and the reductions were maintained stably throughout the rest of the observation period (5 days). All of HbA1c, GA, HDL-C, TP, UA, FIB-4 index, ALP, T-Bil, LDH, $\mathrm{Na}, \mathrm{Cl}, \mathrm{FT} 4$, urinary microalbumin, heart rate, history of smoking, history of diabetic retinopathy, history of cerebrovascular disease, and prior use of thiazolidinedione and insulin were identified as candidate factors associated with the early glucose-lowering effect of dulaglutide observed on day 1. Long-acting
GLP-1 RAs, including dulaglutide, reduce both the fasting and postprandial blood glucose concentrations by causing sustained activation of the GLP-1 receptor and stimulating glucosedependent insulin secretion [23]. However, these findings are based on the long-term studies. There are only three reports on the early-phase effects of dulaglutide; however, the sample sizes in these studies were small, ranging from 12 to 43; in addition, the associations of the early effects of dulaglutide with the patient demographic characteristics or laboratory data or with switching from other incretin-based medications were also not evaluated in these studies [20-22]. This study presented that dulaglutide achieved reduction in BG levels within $24 \mathrm{~h}$ and this might be beneficial for early decision-making on the appropriate regimen for glycemic control, especially in shortterm hospitalized diabetes patients. Further research is warranted focusing on the comparative data for other GLP-1 RAs.

In relation to the pharmacokinetic profile, it has been reported that dulaglutide reaches its maximum plasma concentration at $48 \mathrm{~h}$ after injection, has an elimination half-life of 5 days, and reaches its steady-state concentration between 2 and 4 weeks after weekly administration [22, 24]. Barrington et al. [22] reported reductions of the fasting BG levels and 2-h postprandial BG levels by $48 \mathrm{~h}$ after the first dulaglutide administration. Their study was designed such that blood samples were collected when dulaglutide reached its maximum concentration in the blood; therefore, the data of the first $24 \mathrm{~h}$ were not shown. Matsushita and Inoue $[20,21]$ reported the mean BG levels, daily glucose fluctuations, as assessed by the SD of the 6-point BG levels, mean amplitude of the glycemic excursions (MAGE), and percentage of patients with BG greater than $180 \mathrm{mg} / \mathrm{dL}$ decreased significantly by a day after the first dulaglutide administration. In present study, the daily average preprandial and postprandial BG levels also, which have not been measured in previous studies, decreased significantly by a day after the first dulaglutide administration [20-22]. In a Japanese phase 3 study, median time to maximum concentration $\left(t_{\max }\right)$ was 50.33 (45.87-94.67) $\mathrm{h}$ after single injection of 
$0.75 \mathrm{mg}$ dulaglutide. In that study, plasma dulaglutide concentration at $24 \mathrm{~h}$ reached about $90 \%$ of those at $48 \mathrm{~h}$ (around $38.0 \mathrm{ng} / \mathrm{mL}$ vs. around $42.5 \mathrm{ng} / \mathrm{mL}$ ) [2]. Thus, the plasma concentration of dulaglutide seemed to be elevated enough at $24 \mathrm{~h}$ after first injection to reduce blood glucose level.

Barrington et al. [22] reported a significant increase from the baseline of the area under the curve (AUC) of the CPR after 5 weeks of dulaglutide administration, as compared to placebo. Inoue et al. [21] reported a significant increase of the AUC of CPR $(0-4 \mathrm{~h}$ after dulaglutide administration), as compared to placebo, by the third dulaglutide administration. In two previous studies, no change in the glucagon secretion was observed after 4-5 weeks of dulaglutide administration [21, 22]. However, the baseline fasting CPR, urinary C-peptide, and CPI were not correlated with the $\Delta \mathrm{BG}$ levels, and these factors were not considered after dulaglutide administration in the present study. The contribution of insulin secretion or glucagon secretion to the glycemic control elicited by dulaglutide within a day of its administration requires further investigations. The post hoc analysis of AWARD- 1 to 6 showed that a baseline fasting serum insulin level of $55 \mathrm{pmol} / \mathrm{L}$ or less was associated with a $-0.2 \%$ $(-2.2 \mathrm{mmol} / \mathrm{mol})$ greater mean reduction of the $\mathrm{HbA1c}$, but the influence was considered to be too small to be clinically significant [25]. In another post hoc analysis of AWARD-1, 3, and 6 , greater reduction of the $\mathrm{HbA1c}$ was observed in candidates with a low baseline HOMA2- $\% \beta$ (3.5-43.9\%), but the difference was no longer observed after adjustment for the baseline HbA1c [26]. Dulaglutide may be effective even in patients with severe diabetes, as reduction of the HbA1c was observed irrespective of the beta cell function in a past long-term study [26] as well as in the present study.

While there are no previous reports on the predictors of the immediate glucose-lowering effect of dulaglutide, several studies with observation periods of more than 12 weeks have reported factors related to reduction of the HbA1c by dulaglutide treatment, and the major factor is a relatively high baseline $\mathrm{HbA1c}$ $[18,25,27,28]$. The $\Delta$ fasting BG immediately after the first administration of dulaglutide was found to be associated with the baseline HbA1c and GA in the present study. This finding suggests that poor baseline glycemic control may be associated with greater improvements of the BG levels following administration of dulaglutide, both in the short term and the long term.

Reported factors related to reduction of the HbA1c following dulaglutide treatment other than the baseline HbA1c vary among previous studies. In the post hoc analysis of AWARD-1 to 6, Wysham et al. [25] reported that a lower baseline fasting $\mathrm{BG}$, age 65 years or less, and eGFR of $100 \mathrm{~mL} / \mathrm{min} / 1.73 \mathrm{~m}^{2}$ or less were associated with a greater reduction of the HbA1c following dulaglutide treatment. In a post hoc analysis of phase 3 studies of dulaglutide in Japanese patients with type 2 diabetes conducted by Onishi et al. [28], lower baseline body weight (less than $70 \mathrm{~kg}$ ), lower BMI (less than $25 \mathrm{~kg} / \mathrm{m}^{2}$ ), and higher age (65 years and over) were identified as significant factors. However, the influences of these factors on the reduction of the $\mathrm{HbA1c}$ by a mean value in the range of $-0.05 \%$ to $-0.21 \% \quad(-0.6$ to $-2.2 \mathrm{mmol} / \mathrm{mol}$ ) were considered to be too small and to be of limited clinical significance, and both studies concluded that dulaglutide produced a significant reduction of the HbA1c, irrespective of background factors, except that a higher baseline HbA1c was associated with a $-0.6 \%$ to $-0.8 \%$ ( -6.6 to $-8.8 \mathrm{mmol} / \mathrm{mol}$ ) greater mean reduction of the HbA1c $[25,28]$. Wysham et al. [25] contended that renal dysfunction may lower the endogenous insulin clearance, resulting in a greater degree of reduction of the HbA1c. In that study, patients over the age of 65 years tended to show lower HbA1c and eGFR values but the majority of their participants were aged below 65 years, making it difficult to interpret their results [25]. In the present study, we found no correlations among the $\Delta$ BG levels and patients' age, body weight, BMI, baseline renal function, or baseline fasting BG. Thus, it may be reasonable to conclude that factors other than the baseline HbA1c exert no significant influence on the effectiveness of dulaglutide in the immediate period after its administration. 
According to two previous studies, the duration of diabetes was not associated with the change in the HbA1c achieved with dulaglutide treatment $[18,28]$, but a third study showed that patients with a shorter duration of diabetes showed greater degree of reduction of the HbA1c following dulaglutide treatment [29]. In the present study, the duration of diabetes was not related to the $\triangle B G$ levels, but subjects without a history of diabetic retinopathy and cerebrovascular disease showed greater $\Delta \mathrm{SD}$ of the 6-point BG levels and $\Delta$ fasting BG levels, respectively. There are no previous reports on the influence of diabetic complications on the glucose-lowering effect of dulaglutide. Patients without diabetic complications are likely to have a shorter duration of diabetes, but the results cannot be interpreted clearly, as the influence of the duration of diabetes on the reduction of $\mathrm{HbA} 1 \mathrm{c}$ reported by previous studies is conflicting [18, 28, 29].

In a previous long-term study, patients who were switched from another GLP-1 RA or DPP4 inhibitor to dulaglutide showed significant reduction of the HbA1c, although the degree of reduction was lower than that in patients who were receiving biguanides, thiazolidinediones, sulfonylureas, or insulin, either alone or in combination [29]. However, there are no studies on the effect of switching from DPP4 inhibitors or other GLP-1 RAs to dulaglutide on the immediate effects of the latter on the BG levels so far. Although the short-term study conducted by Matsushita et al. [20] included 7 out of 15 participants with prior history of use of DPP4 inhibitors, evaluation of independent associations between the previously used DPP4 inhibitors and the glucose-lowering effects immediately after the first dulaglutide administration was not presented. This is the first report of patients switched from DPP4 inhibitors to dulaglutide treatment, in whom significant reductions of the BG levels and SD of the 6-point BG levels were demonstrated a day after dulaglutide administration. In addition, patients in the present study who were switched from liraglutide to dulaglutide treatment did not show worsening of the fasting or postbreakfast BG levels in the present study. From these results and the results of past studies, switching from other incretin-based medications to dulaglutide appears to be safe.

The positive correlation between prior use of insulin and $\Delta$ BG levels observed in the present study could be explained by subjects with higher baseline HbA1c values being more likely to be on frequently titrated insulin therapy in a hospitalized situation.

GLP-1 RAs have been shown to improve the lipid and glucose metabolisms in the liver [30]. In previous studies, significant reductions of the serum AST, ALT [31], and gamma-glutamyl transferase $(\gamma$-GTP) levels $[31,32]$, as well as the liver fat content [32], were observed in the dulaglutide treatment arm, as compared to the placebo arm, after 24 weeks of treatment. The positive correlations of the FIB- 4 index, ALP, T-Bil and LDH with the $\Delta$ BG levels observed in the present study could be due to the effects of dulaglutide on the liver fat. Other factors associated with the $\Delta \mathrm{BG}$ levels in the present study include the serum $\mathrm{Na}, \mathrm{Cl}, \mathrm{UA}, \mathrm{HDL}-\mathrm{C}, \mathrm{FT} 4, \mathrm{TP}$, urinary microalbumin, heart rate, prior use of thiazolidinedione, and history of smoking. There are no previous reports on the associations of these factors with the effects of dulaglutide, and because of the exploratory nature of our study, it is not possible to establish causal associations and further studies are needed.

There were several limitations of our study. Firstly, the observed improvement in the glucose profiles following dulaglutide administration could also have been influenced by diet modification, frequent checking of the BG levels, and adjustments of the doses of the antidiabetic medications in the hospitalized patients by the end of the observation period (day 5). Secondly, patients previously treated with incretin-related drugs were not allowed a washout period, making it difficult to precisely determine the contribution of dulaglutide itself to the reduced BG levels. In addition, we analyzed possible factors associated with the immediate effects of dulaglutide, but it was not possible to establish causal relationships because of the exploratory nature of this study. Therefore, a prospective study with strict inclusion criteria, a washout period for incretinrelated drugs, and restriction of adjustments of 
the doses of other antidiabetic drugs, including insulin, is warranted.

\section{CONCLUSIONS}

Dulaglutide achieved reduction in glucose level within $24 \mathrm{~h}$ of the first injection. The reduced BG levels were maintained stably for at least a week in the hospitalized clinical setting. The drug was particularly effective for patients with relatively high baseline HbA1c levels, irrespective of the age, BMI, beta cell function, or duration of diabetes.

\section{ACKNOWLEDGEMENTS}

We would like to thank the participants of the study. We thank Dr Hirokazu Kawano (Yokohama City University) for the data collection, and Misa Katayama for her secretarial assistance.

Funding. This work, and the journal's Rapid Service Fee, was supported in part by Grants-inAid for Scientific Research (C) 20K08866 from MEXT of Japan, from AMED-A*STAR SCICORP for research on cell therapy, and from the Japan IDDM network (to J.S.).

Authorship. All named authors meet the International Committee of Medical Journal Editors (ICMJE) criteria for authorship for this article, take responsibility for the integrity of the work as a whole, and have given their approval for this version of the article to be published.

Authorship Contributions. All authors have contributed to this study at every stage of manuscript development. Jun Shirakawa and Sakiko Terui developed the study concept and design and drafted the manuscript. All authors were involved in data collection, editing the manuscripts and discussion.

Disclosures. Sakiko Terui, Ryoichi Akamatsu, Masanori Arai, Ryota Inoue, Tomoko Okuyama, Mayu Kyohara, Yu Togashi, Jinghe
Li, Takahiro Tsuno, Daisuke Miyashita, Yasuo Terauchi, and Jun Shirakawa confirm that they have nothing to disclose.

Compliance with Ethics Guidelines. This study was conducted with the approval of the ethics committee of Yokohama City University Hospital (B191100009). The study protocol was in compliance with the principles outlined in the 1964 Declaration of Helsinki and its later amendments. Written informed consent from the subjects was not required because of the anonymized nature of the data collected from the existing medical records. We informed the participants about the objectives, method, research period, and types of data collected in this study, and of their right to refuse participation in the study via a notice put up on the website of Yokohama City University Hospital.

Data Availability. The datasets generated during and/or analyzed during the current study will be made available by the corresponding author upon reasonable request.

Open Access. This article is licensed under a Creative Commons Attribution-NonCommercial 4.0 International License, which permits any non-commercial use, sharing, adaptation, distribution and reproduction in any medium or format, as long as you give appropriate credit to the original author(s) and the source, provide a link to the Creative Commons licence, and indicate if changes were made. The images or other third party material in this article are included in the article's Creative Commons licence, unless indicated otherwise in a credit line to the material. If material is not included in the article's Creative Commons licence and your intended use is not permitted by statutory regulation or exceeds the permitted use, you will need to obtain permission directly from the copyright holder. To view a copy of this licence, visit http://creativecommons.org/licenses/by$\mathrm{nc} / 4.0 /$. 


\section{REFERENCES}

1. Glaesner W, Mark Vick A, Millican R, et al. Engineering and characterization of the long-acting glucagon-like peptide-1 analogue LY2189265, an Fc fusion protein. Diabetes Metab Res Rev. 2010;26(4): 287-96.

2. Sumitomo Dainippon Pharma Co., Ltd. TRULICITY Subcutaneous Injection ATEOS Interview Form 9th edition. 2021.

3. Wysham C, Blevins T, Arakaki R, et al. Efficacy and safety of dulaglutide added onto pioglitazone and metformin versus exenatide in type 2 diabetes in a randomized controlled trial (AWARD-1). Diabetes Care. 2014;37(8):2159-67.

4. Giorgino F, Benroubi M, Sun J-H, Zimmermann AG, Pechtner V. Efficacy and safety of once-weekly dulaglutide versus insulin glargine in patients with type 2 diabetes on metformin and glimepiride (AWARD-2). Diabetes Care. 2015;38(12):2241-9.

5. Blonde L, Jendle J, Gross J, et al. Once-weekly dulaglutide versus bedtime insulin glargine, both in combination with prandial insulin lispro, in patients with type 2 diabetes (AWARD-4): a randomised, open-label, phase 3, non-inferiority study. The Lancet. 2015;385(9982):2057-66.

6. Nauck M, Weinstock RS, Umpierrez GE, Guerci B, Skrivanek Z, Milicevic Z. Efficacy and safety of dulaglutide versus sitagliptin after 52 weeks in type 2 diabetes in a randomized controlled trial (AWARD-5). Diabetes Care. 2014;37(8):2149-58.

7. Dungan KM, Povedano ST, Forst T, et al. Onceweekly dulaglutide versus once-daily liraglutide in metformin-treated patients with type 2 diabetes (AWARD-6): a randomised, open-label, phase 3, non-inferiority trial. The Lancet. 2014;384(9951): 1349-57.

8. Dungan KM, Weitgasser R, Perez Manghi F, et al. A 24-week study to evaluate the efficacy and safety of once-weekly dulaglutide added on to glimepiride in type 2 diabetes (AWARD-8). Diabetes Obes Metab. 2016;18(5):475-82.

9. Pozzilli P, Norwood P, Jódar E, et al. Placebo-controlled, randomized trial of the addition of onceweekly glucagon-like peptide-1 receptor agonist dulaglutide to titrated daily insulin glargine in patients with type 2 diabetes (AWARD-9). Diabetes Obes Metab. 2017;19(7):1024-31.

10. Umpierrez G, Tofé Povedano S, Pérez Manghi F, Shurzinske L, Pechtner V. Efficacy and safety of dulaglutide monotherapy versus metformin in type 2 diabetes in a randomized controlled trial (AWARD-3). Diabetes Care. 2014;37(8):2168-76.

11. Reaney M, Yu M, Lakshmanan M, Pechtner V, van Brunt K. Treatment satisfaction in people with type 2 diabetes mellitus treated with once-weekly dulaglutide: data from the AWARD-1 and AWARD3 clinical trials. Diabetes Obes Metab. 2015;17(9): 896-903.

12. Robinson S, Boye KS, Mody R, et al. Real-world effectiveness of dulaglutide in patients with type 2 diabetes mellitus: a literature review. Diabetes Ther. 2020;11(7):1437-66.

13. Mody R, Yu M, Nepal B, Konig M, Grabner M. Adherence and persistence among patients with type 2 diabetes initiating dulaglutide compared with semaglutide and exenatide BCise: 6-month follow-up from US real-world data. Diabetes Obes Metab. 2021;23(1):106-15.

14. Ishigaki Y, Strizek A, Aranishi T, et al. Glucagon-like peptide-1 receptor agonist utilization in type 2 diabetes in Japan: a retrospective database analysis (JDDM 57). Diabetes Ther. 2021;12(1):345-61.

15. Gerstein HC, Colhoun HM, Dagenais GR, et al. Dulaglutide and renal outcomes in type 2 diabetes: an exploratory analysis of the REWIND randomised, placebo-controlled trial. The Lancet. 2019;394(10193):131-8.

16. Gerstein HC, Colhoun HM, Dagenais GR, et al. Dulaglutide and cardiovascular outcomes in type 2 diabetes (REWIND): a double-blind, randomised placebo-controlled trial. The Lancet. 2019;394(10193):121-30.

17. U.S. Food and Drug Administration, Drugs@FDA. FDA-Approved Drugs, Labels for TRULICITY. 2020.

18. Gallwitz B, Dagogo-Jack S, Thieu V, et al. Effect of once-weekly dulaglutide on glycated haemoglobin (HbA1c) and fasting blood glucose in patient subpopulations by gender, duration of diabetes and baseline HbA1c. Diabetes Obes Metab. 2018;20(2): 409-18.

19. Grunberger G, Forst T, Fernández Landó L, et al. Early fasting glucose measurements can predict later glycaemic response to once weekly dulaglutide. Diabet Med. 2016;33(3):391-4.

20. Matsushita M, Chujo D, Tonoike M, Kajio $H$. Durability of glucose-lowering effect of the first administration of dulaglutide: a retrospective, single-center, single-arm study. Diabetes Ther. 2018;9(5):2127-32.

21. Inoue M, Shiramoto M, Oura T, Nasu R, Nakano M, Takeuchi M. Effect of once-weekly dulaglutide on 
glucose levels in Japanese patients with type 2 diabetes: findings from a phase 4 , randomized controlled trial. Diabetes Ther. 2019;10(3):1019-27.

22. Barrington P, Chien JY, Showalter $\mathrm{HDH}$, et al. A 5 -week study of the pharmacokinetics and pharmacodynamics of LY2189265, a novel, long-acting glucagon-like peptide- 1 analogue, in patients with type 2 diabetes. Diabetes Obes Metab. 2011;13(5): 426-33.

23. Gentilella R, Pechtner V, Corcos A, Consoli A. Glucagon-like peptide- 1 receptor agonists in type 2 diabetes treatment: are they all the same? Diabetes Metab Res Rev. 2019;35(1):e3070.

24. Geiser JS, Heathman MA, Cui X, et al. Clinical pharmacokinetics of dulaglutide in patients with type 2 diabetes: analyses of data from clinical trials. Clin Pharmacokinet. 2016;55(5):625-34.

25. Wysham C, Guerci B, D'Alessio D, Jia N, Botros FT. Baseline factors associated with glycaemic response to treatment with once-weekly dulaglutide in patients with type 2 diabetes. Diabetes Obes Metab. 2016;18(11):1138-42.

26. Mathieu C, Del Prato S, Botros FT, et al. Effect of once weekly dulaglutide by baseline beta-cell function in people with type 2 diabetes in the AWARD programme. Diabetes Obes Metab. 2018;20(8):2023-8.
27. DeFronzo RA, Stonehouse AH, Han J, Wintle ME. Relationship of baseline HbA1c and efficacy of current glucose-lowering therapies: a meta-analysis of randomized clinical trials. Diabet Med. 2010;27(3):309-17.

28. Onishi Y, Oura T, Nishiyama H, Ohyama S, Takeuchi M, Iwamoto N. Subgroup analysis of phase 3 studies of dulaglutide in Japanese patients with type 2 diabetes. Endocr J. 2016;63(3):263-73.

29. Berra CC, Resi V, Mirani M, et al. Clinical efficacy and predictors of response to dulaglutide in type-2 diabetes. Pharmacol Res. 2020;159:104996.

30. Seino Y, Yabe D. Glucose-dependent insulinotropic polypeptide and glucagon-like peptide-1: incretin actions beyond the pancreas. J Diabetes Investig. 2013;4(2):108-30.

31. Cusi K, Sattar N, Garcia-Perez LE, et al. Dulaglutide decreases plasma aminotransferases in people with type 2 diabetes in a pattern consistent with liver fat reduction: a post hoc analysis of the AWARD programme. Diabet Med. 2018;35(10):1434-9.

32. Kuchay MS, Krishan S, Mishra SK, et al. Effect of dulaglutide on liver fat in patients with type 2 diabetes and NAFLD: randomised controlled trial (D-LIFT trial). Diabetologia. 2020;63(11):2434-45. 